\title{
Sex Differences in the Correlation Between Restricted Ankle Dorsiflexion and Knee Joint Biomechanics During Gait-Focus on the Knee Adduction Moment-
}

\author{
Susumu Ota ${ }^{1 *}$, Remi Fujita ${ }^{1}$, Makoto Ueda $^{2}$, Keita Aimoto ${ }^{3}$, Ai Nakanishi ${ }^{2}$ and Yasuo Suzuki ${ }^{4}$ \\ ${ }^{1}$ Department of Rehabilitation and Care, Seijoh University, Tokai, Achi, Japan \\ ${ }^{2}$ Division of Rehabilitation, Syutaikai Hospital, Yokkaichi, Achi, Japan
}

${ }^{3}$ Department of Rehabilitation Medicine, National Center for Geriatrics and Gerontology, Obu, Achi, Japan

${ }^{4}$ Department of Human Care Engineering, Nihon Fukushi University, Handa, Achi, Japan

*Corresponding author: Susumu Ota, Department of Rehabilitation and Care, Seijoh University, Tokai, Achi, Japan

\section{ARTICLE INFO}

Received: 幽 November 14, 2019

Published: 豐 December 05, 2019

Citation: Susumu Ota, Remi Fujita, Makoto Ueda, Keita Aimoto, Ai Nakanishi, Yasuo Suzuki. Sex Differences in the Correlation Between Restricted Ankle Dorsiflexion and Knee Joint Biomechanics During Gait -Focus on the Knee Adduction Moment-. Biomed J Sci \& Tech Res 23(4)-2019. BJSTR. MS.ID.003932.

Keywords: Ankle Dorsiflexion Angle; Knee Joint Biomechanics; Gait; Terminal Stance; Sex Difference

\section{ABSTRACT}

Potential differences between sexes in knee joint biomechanics due to restricted ankle dorsiflexion (DF) may influence the increased prevalence of osteoarthritis (OA) in women. The purpose of this study is to investigate sex differences in the knee adduction moment (KAM) during gait under unrestricted and restricted ankle DF conditions. Forty-nine healthy volunteers ( 24 men: $21.7 \pm 2.5$ years old; 25 women: $21.3 \pm 1.2$ years old) were fitted with a custom-made ankle brace to restrict ankle DF. The ankle DF angle, knee extension angle, and KAM ( $1^{\text {st }}$ and $2^{\text {nd }}$ halves of the stance phase) were measured during the stance phase while walking. The decrease in the ankle DF angle correlated with an increase in the knee extension angle during the $1^{\text {st }}$ half of the stance phase in both sexes ( $\mathrm{r}=0.52$ and 0.61 , both $\mathrm{p}<0.01$, respectively). The ankle DF decrease correlated with an increase in the $1^{\text {st }}$ and $2^{\text {nd }} \mathrm{KAM}$ only in women $(\mathrm{r}=-0.50$ and $\mathrm{p}<0.05$; $\mathrm{r}=-0.53$ and $\mathrm{p}<0.01$, respectively).Multiple regression analysis revealed that decreases in the ankle DF and knee flexion angle accounted for $24 \%$ of the increase in the $2^{\text {nd }} \mathrm{KAM}$ in women. Restricted ankle DF was related to an increase in the $1^{\text {st }}$ and $2^{\text {nd }}$ peak KAM in women, but not in men. In particular, the increase in the $2^{\text {nd }}$ KAM in women related to a greater knee extension angle (hyperextension) and a smaller ankle DF angle. The present findings support the use of range of motion exercises to increase ankle DF to reduce KAM and prevent knee $\mathrm{OA}$, especially in women.

Abbreviations: DF: Ankle Dorsiflexion; KAM: Knee Adduction Moment; BMI: Body Mass Index; ES: Effect Size

\section{Introduction}

Knee osteoarthritis $(\mathrm{OA})$ is a highly prevalent joint disease among middle-aged and elderly people [1,2]. The prevalence of knee OA is higher in women than in men [1]. Mechanical stress (medial compartment contact force) to the knee joint relates to this prevalence $[3,4]$, and the knee adduction moment (KAM) during gait is a surrogate value of the medial compression force $[5,6]$. Based on longitudinal studies [7-9], higher KAM is a risk factor for medial knee OA. Several studies report that decreasing the KAM during the gait is an effective strategy for preventing knee OA [10-13].
On the other hand, a previous biomechanical gait study showed that restricting the ankle dorsiflexion (DF) angle to $\sim 8^{\circ}$ during the terminal stance increases the KAM and the knee extension angle (knee genu recurvatum) in healthy adults [14], and suggested that improving and/or maintaining the ankle DF angle could prevent medial knee OA. Although some studies report that women have greater knee joint laxity (hyperextension) compared with men, potential sex differences in the biomechanical effects due to a restricted ankle DF were not investigated. 
The ankle DF angle is often restricted as a result of an ankle sprain [15], ankle fracture [16], or Achilles tendon injuries [17]. In addition, aging may reduce ankle DF, especially in women $[18,19]$. Women have

1) a high prevalence of medial knee OA [1],

2) age-related decreases in the ankle DF angle [18] and

3) greater knee-joint extension [20-22] compared with men.

Although sex differences may affect the gait mechanism when the ankle DF is restricted, no studies have yet investigated the potential sex-related biomechanical effects of reduced ankle DF during gait. The present study investigated whether the correlation between restricted ankle DF and knee joint biomechanics during the gait differs between the sexes, focusing on the KAM. We hypothesized that a reduced ankle DF would correlate with an increase in the KAM and a decreased knee flexion angle (increased knee extension) during the terminal stance phase, which usually requires ankle DF, to a greater extent in women than in men.

\section{Methods}

\section{Participants}

Forty-nine healthy volunteers (24 men and 25 women) participated in the study. Individuals from Nagoya University responded to flyers posted on campus and verbal requests for subjects. Subjects were excluded from participation if they had a current lower extremity injury, knee OA, history of ankle injury, or any medical condition that would affect their ability to perform the study tasks. The Ethics Committee of Nagoya University approved the study, and, after the nature of the study was explained to the participants, all subjects provided written informed consent to participate in the study.

\section{Brace to Restrict Ankle DF}

A custom-made ankle brace for the right ankle (Matsumoto P \& O Co., Ltd., Komaki, Japan) was used to restrict ankle DF using a dial lock joint (Figure 1) while allowing for unrestricted plantar flexion. The brace was made of Torelac clear material and the lock was adjustable to restrict motion at various degrees of ankle DF. The restricted condition was set to $0^{\circ}$ of DF or natural alignment, based on a previous study [14] demonstrating a significantly increased KAM under this condition compared with the unrestricted condition. Ankle DF was examined in the unrestricted condition and restricted condition (restricted to $0^{\circ}$ ) in a non-weight-bearing state. Subjects wore the ankle brace during the unrestricted condition, but the sagittal plane ankle range of motion was not restricted.

\section{Instrumentation}

Three-dimensional kinematic data were obtained using a 7-camera motion analysis system (Vicon Nexus; Vicon Motion System, Oxford, UK). Kinematic data were sampled at $120 \mathrm{~Hz}$ and digitally recorded. Ground reaction forces were collected at $120 \mathrm{~Hz}$ using custom-made two-piece (left-right) force plates (Kistler Z11942; 2×0.8 m, Z12091; 2×0.4 m; Kistler, Amhurst, NY) embedded in the floor. The motion capture and force plates were temporally synchronized.

\section{Procedures}

Data were collected at the gait analysis laboratory at Rosai Rehabilitation Engineering Center. Thirty-five reflective markers (14-mm diameter) were attached to anatomic locations according to the VICON Plug-in Gait marker placement protocol for full-body (35 markers, 15 segments) evaluation. The markers defined the left and right foot, left and right lower legs, left and right thighs, pelvis, thorax, left and right upper arms, left and right forearms, left and right hands, and the head. All subjects wore compression shorts and a swim cap, and females also wore a sport bra. Head, thigh, and pelvic markers (anterior and posterior superior iliac spine) were attached to the clothes. The other markers were attached to the skin. Ankle markers were attached to the heel and lateral malleolus, and 2nd metatarsal head on the skin without attachment to the ankle brace (Figure 1). Therefore, the markers could be kept in the same place under all conditions. Double-sided tape was used to attach all anatomic markers.

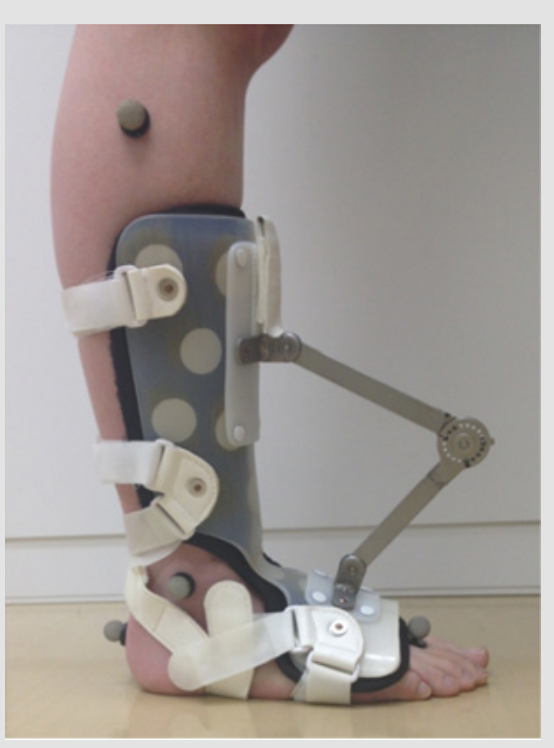

Figure 1: Custom-made ankle brace.

Note: The brace limits ankle dorsiflexion using a dial lock joint to allow for plantar flexion.

Each subject was evaluated in two brace conditions (unrestricted and restricted) in random order. Participants performed the tasks barefoot with only the right foot secured in the brace. Cadence was controlled by a metronome set at the standard pace for Japanese men and women according to a previous report (113 steps/minute and 115 steps/minute, respectively) [23]. Subjects were asked to walk along a 10-m walkway, and three trials under each brace condition were performed. Practice trials allowed subjects to become familiar with the brace. 


\section{Data Analysis}

The Vicon Plug-in Gait model was used to quantify the ankle sagittal plane angle, and knee sagittal and frontal plane angles. Kinematic data were filtered using the Woltring filter with a predicted mean squared error value of 20. The Plug-in Gait model was used to define rigid body segments and joint angles between these segments. The hip joint center was defined using the Davis method [24]. The knee and ankle joint centers were defined as the midpoint between the lateral and medial femoral epicondyle and medial and lateral malleolus, respectively. Euler angles were used to determine relative segmental motion, and joint angles were calculated based on segmental motion of the distal segment about a fixed point on the proximal segment. Ankle DF, knee flexion (negative value indicates knee hyperextension), and knee adduction angle were positive. Kinematics, segment masses, and moments of inertia were used in standard inverse dynamics equations to calculate the external knee joint moments. External knee flexion and adduction moments were positive. The knee joint moments were normalized to body mass.

The right foot data of the stance phase were used in the final analysis. All data were normalized to $100 \%$ of the stance phase. The biomechanical values used were the peaks of the $1^{\text {st }}$ half $(0 \%-50 \%)$ and $2^{\text {nd }}$ half of the stance phases (50\%-100\%). The peak ankle DF angles, peak knee flexion angle during the $1^{\text {st }}$ half, minimum peak of the knee flexion angle during the $2^{\text {nd }}$ half, peak knee adduction angles, peak knee flexion moment during the 1st half, negative peak of the knee flexion moment, and peak knee adduction moments were measured for the braced (right) limb. For each subject, dependent variables of interest were identified from each trial and averaged over three trials.

Intratester reliability of the kinematics and kinetics were assessed using the intraclass correlation coefficient in the same measurement setting as described in a previous study [14]. The KAM, knee adduction angle, knee flexion angle, and ankle DF angle had an intraclass correlation coefficient ranging from 0.91 to 0.99 , and that of the knee flexion moment was 0.59 .

\section{Statistical Analyses}

Prior to the analysis, normal distributions were confirmed by Shapiro-Wilk analysis. Differences between the biomechanical data under the unrestricted and restricted conditions were assessed using a paired t-test (normal distribution) or Wilcoxon signedrank test (non-normal distribution). Differences in values between men and women were assessed using an unpaired t-test (normal distribution) or Mann-Whitney U test (non-normal distribution). A p-value of less than 0.05 was considered statistically significant, and effect size (ES) was also determined. The relationship between the changes in ankle DF angle, the KAM, and other biomechanical values with and without restricted conditions was testing using Pearson's correlation (normal distribution) or Spearman's ranked correlation (non-normal distribution). All statistical analyses were performed with SPSS, version 16.0 (IBM Japan, Chuo Ward, Tokyo, Japan). Because the brace was only one size, the amount of the ankle DF angle restriction was not the same for each subject. Therefore, the present study investigated the correlation of those biomechanical changes as the main outcome.

\section{Result}

Mean (standard deviation) of the age, height, and body mass index (BMI) of all participants were $21.8 \pm 2.2$ years, $165.2 \pm 7.7 \mathrm{~cm}$, and $20.5 \pm 1.9 \mathrm{~kg} / \mathrm{m}^{2}$, respectively (men: $21.7 \pm 2.5$ years, $169.6 \pm$ $5.4 \mathrm{~cm}$, and $20.8 \pm 1.8 \mathrm{~kg} / \mathrm{m}^{2}$, respectively; women: $21.3 \pm 1.2$ years, $159.2 \pm 5.1 \mathrm{~cm}$, and $20.0 \pm 1.5 \mathrm{~kg} / \mathrm{m}^{2}$, respectively). Age and BMI did not differ significantly between men and women; height in men was significantly higher than in women $(\mathrm{P}<0.01)$ Table 1 shows the characteristics and changes in the biomechanical values due to the restricted ankle range of motion during the $1^{\text {st }}$ and $2^{\text {nd }}$ halves of the stance phase, and the sex differences in those values. Figures 2-4 show the ankle DF angle and knee joint biomechanics values under unrestricted and restricted conditions during the stance phase in men and women. Peak ankle DF angles for the unrestricted and restricted conditions were $14.1 \pm 4.0^{\circ}$ and $6.9 \pm 5.3^{\circ}$ in men $(\mathrm{P}<$ $0.01, \mathrm{ES}=1.52)$, and $10.1 \pm 5.6^{\circ}$ and $2.8 \pm 4.1^{\circ}$ in women $(\mathrm{P}<0.01$, ES $=1.47)$. The brace successfully reduced ankle DF during the gait (Table 1).

Table 1: Characteristics and changes in biomechanical values due to restricted ankle range of motion during the $1^{\text {st }}(0 \%-50 \%)$ and $2^{\text {nd }}$ halves $(50 \%-100 \%)$ of the stance phase.

\begin{tabular}{|c|c|c|c|c|c|}
\hline \multirow{2}{*}{$\mathbf{0} \%$ to $50 \%$} & \multicolumn{2}{|r|}{ Unrestricted } & \multicolumn{2}{|r|}{ Restricted } & \multirow{2}{*}{$\begin{array}{c}\text { Unrestricted vs Restricted } \\
\text { P Value (ES) }\end{array}$} \\
\hline & Mean (SD) & Men vs Women P Value (ES) & Mean (SD) & Men vs Women P Value (ES) & \\
\hline \multicolumn{6}{|c|}{ Ankle DF Angle $\left({ }^{\circ}\right)$} \\
\hline All & $5.5(4.0)$ & & $1.1(4.4)$ & & $<0.001(1.10)$ \\
\hline men & $7.4(3.5)$ & $<0.001$ & $2.9(4.3)$ & 0.004 & $<0.001(1.29)$ \\
\hline women & $3.7(3.7)$ & {$[1.01]$} & $-0.6(3.8)$ & {$[0.88]$} & $<0.001(1.17)$ \\
\hline \multicolumn{6}{|c|}{ Knee Flexion Angle $\left({ }^{\circ}\right)$} \\
\hline All & $19.3(7.3)^{*}$ & & $15.4(7.0)$ & & $<0.001(0.53)$ \\
\hline
\end{tabular}




\begin{tabular}{|c|c|c|c|c|c|}
\hline $\begin{array}{c}\text { Men } \\
\text { Women }\end{array}$ & $\begin{array}{c}21.1(7.1)^{*} \\
17.5(7.1)\end{array}$ & $\begin{array}{c}0.032^{* *} \\
{[0.51]}\end{array}$ & $\begin{array}{l}16.6(6.8) \\
14.3(7.2)\end{array}$ & $\begin{array}{l}0.261 \\
{[0.33]}\end{array}$ & $\begin{array}{c}<0.001(0.64) \\
0.001(0.44)\end{array}$ \\
\hline \multicolumn{6}{|c|}{ Knee Flexion Moment (Nm/kg) } \\
\hline All & $0.81(0.36)$ & & $0.65(0.30)$ & & $<0.001(0.45)$ \\
\hline men & $0.89(0.36)$ & 0.159 & $0.73(0.31)$ & 0.094 & $<0.001(0.45)$ \\
\hline women & $0.74(0.35)$ & {$[0.41]$} & $0.58(0.28)$ & {$[0.49]$} & $<0.001(0.45)$ \\
\hline \multicolumn{6}{|c|}{ Knee Adduction Angle $\left({ }^{\circ}\right)$} \\
\hline All & $2.6(4.2)$ & & $2.9(4.0)$ & & $0.384(0.06)$ \\
\hline men & $3.3(4.9)$ & 0.266 & $3.7(4.7)$ & 0.183 & $0.398(0.07)$ \\
\hline women & $2.0(3.3)$ & {$[0.33]$} & $2.1(3.2)$ & {$[0.39]$} & $0.731(0.04)$ \\
\hline \multicolumn{6}{|c|}{ Knee Adduction Moment (Nm/kg) } \\
\hline Allmen & $0.38(0.18)$ & & $0.39(0.16)$ & 0191 & $0.236(0.10)$ \\
\hline women & $0.36(0.17)$ & 0.485 & $0.36(0.17)$ & & $0.860(0.02)$ \\
\hline & $0.40(0.18)$ & {$[0.20]$} & $0.42(0.14)$ & {$[0.39]$} & $0.139(0.17)$ \\
\hline \multicolumn{6}{|c|}{$50 \%$ to $100 \%$} \\
\hline \multicolumn{6}{|c|}{ Ankle DF Angle $\left(^{\circ}\right)$} \\
\hline All & $12.0(5.3)$ & & $4.8(5.1)$ & & $<0.001(1.38)$ \\
\hline men & $14.1(4.0)$ & 0.006 & $6.9(5.3)$ & 0.004 & $<0.001(1.52)$ \\
\hline women & $10.1(5.6)$ & {$[0.82]$} & $2.8(4.1)$ & {$[0.87]$} & $<0.001(1.47)$ \\
\hline Knee flexion angle $\left({ }^{\circ}\right)$ & $6.1(5.7)$ & & $0.98(6.7)$ & & $<0.001(0.82)$ \\
\hline All Men & $9.1(4.7)$ & $<0.001$ & $4.1(6.3)$ & 0.001 & $<0.001(0.91)$ \\
\hline Women & $3.2(5.2)$ & {$[1.19]$} & $-2.0(5.7)$ & {$[1.01]$} & $<0.001(0.96)$ \\
\hline \multicolumn{6}{|c|}{ Knee Flexion Moment (Nm/kg) } \\
\hline All & $-0.1(0.3)$ & & $-0.2(0.2)$ & & $0.019(0.30)$ \\
\hline men & $0.003(0.2)$ & 0.005 & $-0.07(0.2)$ & 0.001 & $0.005(0.32)$ \\
\hline women & $-0.2(0.2)$ & {$[0.85]$} & $-0.3(0.2)$ & {$[0.98]$} & $0.189(0.34)$ \\
\hline \multicolumn{6}{|c|}{ Knee Adduction Angle $\left({ }^{\circ}\right)$} \\
\hline All & $1.6(3.8)$ & & $2.2(3.9)$ & & $0.006(0.14)$ \\
\hline men & $2.1(4.4)$ & 0.366 & $2.9(4.4)$ & 0.221 & $0.010(0.17)$ \\
\hline women & $1.1(3.1)$ & {$[0.26]$} & $1.5(3.3)$ & {$[0.35]$} & $0.192(0.11)$ \\
\hline \multicolumn{6}{|c|}{ Knee Adduction Moment (Nm/kg) } \\
\hline All & $0.37(0.13)$ & & $0.45(0.13)$ & & $<0.001(0.58)$ \\
\hline men & $0.37(0.13)$ & 0.911 & $0.42(0.15)$ & 0.239 & $<0.011(0.35)$ \\
\hline women & $0.37(0.12)$ & {$[0.03]$} & $0.47(0.12)$ & {$[0.34]$} & $<0.001(0.84)$ \\
\hline
\end{tabular}

Note: ES, effect size; * Non-normal distribution; ** Mann-Whitney U test

Table 2 shows the correlations among the changes in the ankle $\mathrm{DF}$ angle, KAM, and other biomechanical values. A decrease in ankle DF significantly correlated with a decrease in knee flexion angle (decreased knee extension angle) during the $1^{\text {st }}$ half of the stance phase in both men and women $(\mathrm{r}=0.52$ and 0.61 , both $\mathrm{P}<0.01)$. In the $2^{\text {nd }}$ half of the stance phase, however, the correlation was obtained only in men $(\mathrm{r}=0.65, \mathrm{P}<0.01)$. On the other hand, the increase in the KAM correlated significantly with reduced ankle DF in both halves of the stance phase only in women ( $r=-0.50$ and $\mathrm{P}<0.05$ and $\mathrm{r}=-0.53$ and $\mathrm{P}<0.01$, respectively). An increase in the KAM also correlated with a decreased knee flexion angle (increased knee extension angle) during the 2nd half of the stance phase in women $(\mathrm{r}=-0.64, \mathrm{P}<0.01)$. 
Table 2: Unrestricted and restricted ankle range of motion differences in the correlation coefficients of biomechanical values during the $1^{\text {st }}(0 \%-50 \%)$ and $2^{\text {nd }}$ halves $(50 \%-100 \%)$ of the stance phase.

\begin{tabular}{|c|c|c|c|c|}
\hline $0 \%$ to $50 \%$ & $\begin{array}{c}\text { Change in Ankle DF } \\
\text { Angle }\end{array}$ & $\begin{array}{c}\text { Change in Knee Flexion } \\
\text { Angle }\end{array}$ & $\begin{array}{c}\text { Change in Knee Flexion } \\
\text { Moment }\end{array}$ & $\begin{array}{l}\text { Change in Knee Adduc- } \\
\text { tion Angle }\end{array}$ \\
\hline \multicolumn{5}{|c|}{ Men } \\
\hline Change in knee flexion angle & $0.52^{* *}$ & & & \\
\hline Change in knee flexion moment & 0.35 & 0.30 & & \\
\hline Change in knee adduction angle & -0.19 & -0.25 & -0.14 & \\
\hline Change in knee adduction moment & -0.23 & -0.14 & $-0.53^{* *}$ & 0.09 \\
\hline \multicolumn{5}{|c|}{ Women } \\
\hline Change in knee flexion angle & $0.61^{* *}$ & & & \\
\hline Change in knee flexion moment & 0.18 & $0.49^{*}$ & & \\
\hline Change in knee adduction angle & -0.08 & 0.27 & 0.35 & \\
\hline Change in knee adduction moment & $-0.50^{*}$ & -0.12 & 0.08 & 0.08 \\
\hline \multicolumn{5}{|c|}{$50 \%$ to $100 \%$} \\
\hline \multicolumn{5}{|c|}{ Men } \\
\hline Change in knee flexion angle & $0.65^{* *}$ & & & \\
\hline Change in knee flexion moment & -0.34 & 0.16 & & \\
\hline Change in knee adduction angle & -0.09 & $-0.45^{*}$ & -0.03 & \\
\hline Change in knee adduction moment & -0.18 & -0.29 & -0.22 & 0.21 \\
\hline \multicolumn{5}{|c|}{ Women } \\
\hline Change in knee flexion angle & 0.36 & & & \\
\hline Change in knee flexion moment & $-0.56^{* *}$ & 0.06 & & \\
\hline Change in knee adduction angle & -0.16 & -0.13 & 0.34 & \\
\hline Change in knee adduction moment & $-0.53^{* *}$ & $-0.64^{* *}$ & 0.10 & -0.01 \\
\hline
\end{tabular}

Note: ${ }^{*} \mathrm{P}<0.05 ;{ }^{* *} \mathrm{P}<0.01$

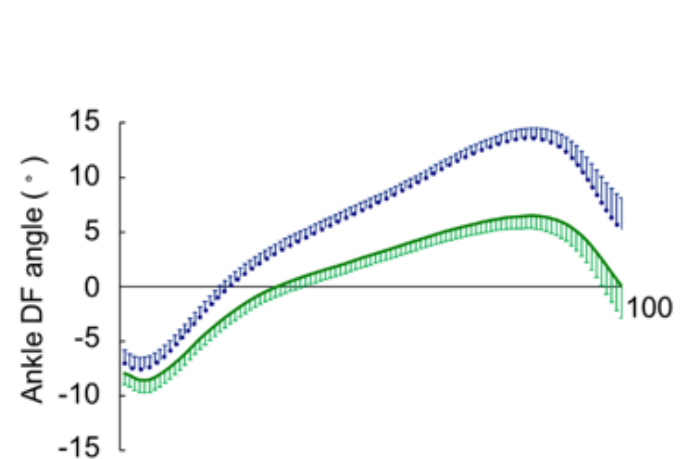

$\%$ Stance Phase

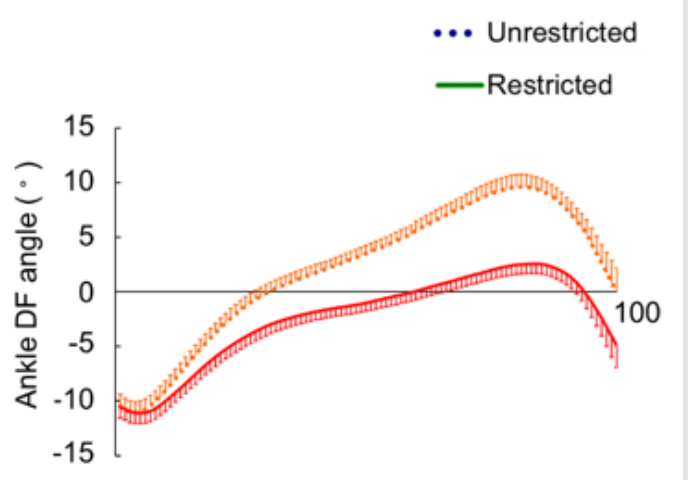

$\%$ Stance Phase

A. Men

B. Women

Figure 2: Ankle dorsiflexion angles with standard error bars during stance phase.

Note: A: Men; B: Women. Dotted lines represent the unrestricted ankle dorsiflexion condition. Solid lines represent the restricted ankle dorsiflexion condition. 


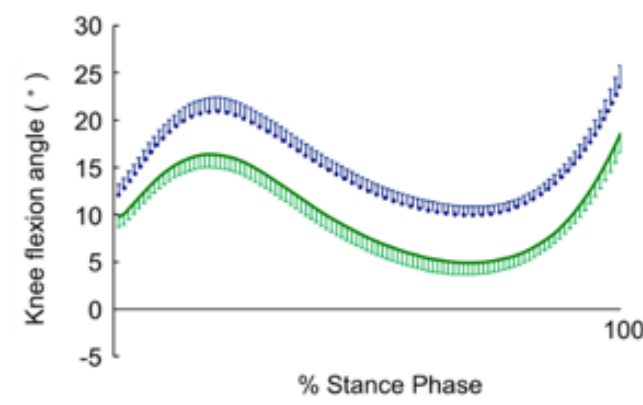

A. Knee flexion angle

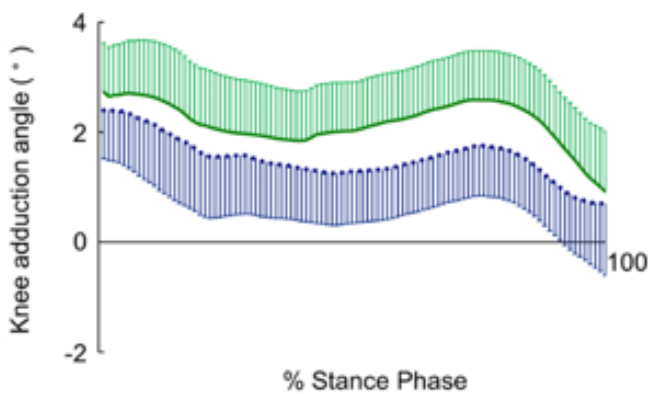

C. Knee adduction angle

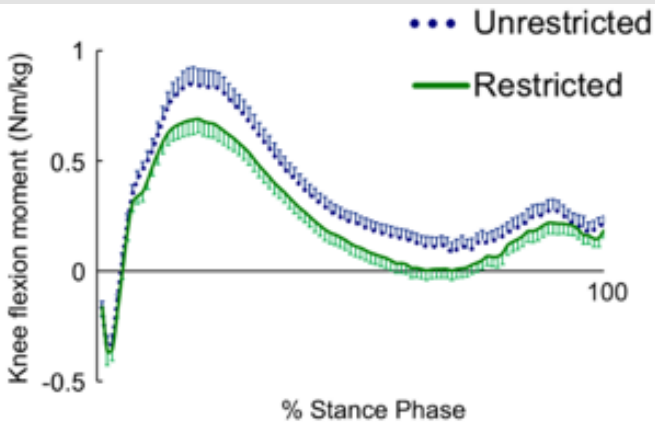

B. Knee flexion moment

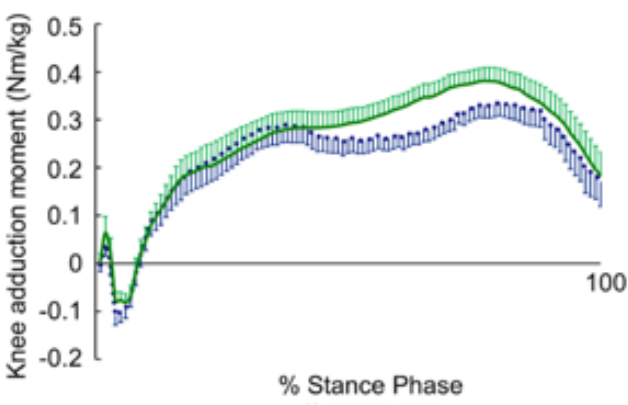

D. Knee adduction moment

Figure 3: Knee kinematics and kinetics with standard error bars during stance phase in men.

Note: A: Knee Flexion Angle; B: Knee Flexion Moment; C: Knee Adduction Angle; D: Knee Adduction Moment. Dotted lines represent the unrestricted ankle dorsiflexion condition. Solid lines represent the restricted ankle dorsiflexion condition. The $\mathrm{X}$-axes show the percent stance phase of one gait cycle.

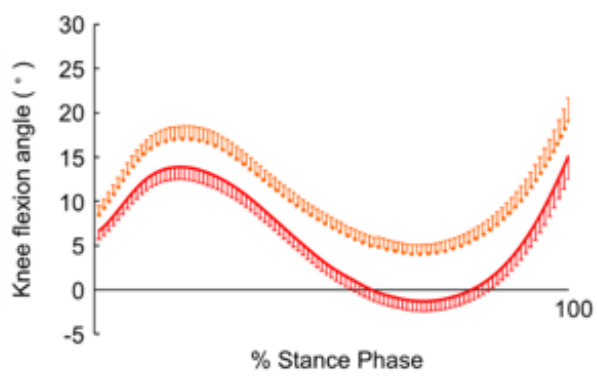

A. Knee flexion angle

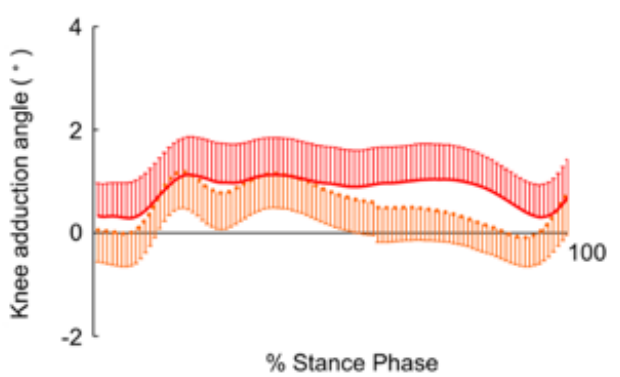

C. Knee adduction angle

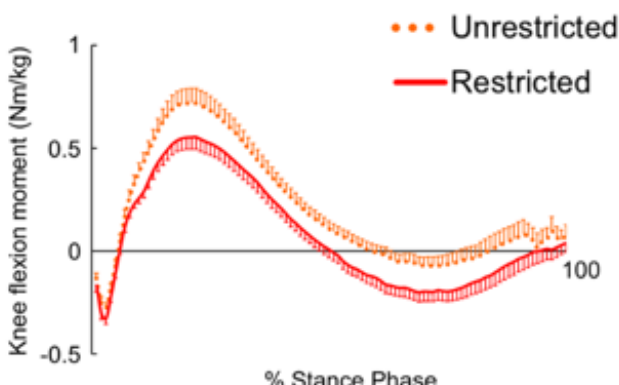

B. Knee flexion moment

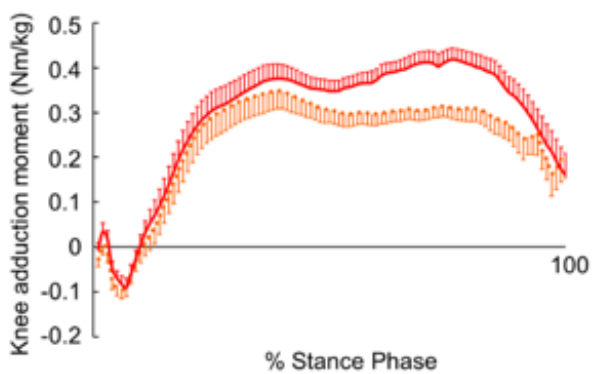

D. Knee adduction moment

Figure 4: Knee kinematics and kinetics with standard error bars during the stance phase in women.

Note: A: Knee Flexion Angle; B: Knee Flexion Moment; C: Knee Adduction Angle; D: Knee Adduction Moment. Dotted lines represent the unrestricted ankle dorsiflexion condition. Solid lines represent the restricted ankle dorsiflexion condition. The $\mathrm{X}$-axes show the percent stance phase of one gait cycle. 


\section{Discussion}

The main findings of the present study focusing on the KAM were that restricted ankle DF during the $1^{\text {st }}$ and $2^{\text {nd }}$ halves of the stance phase significantly correlated with an increase in the KAM only in women. In a healthy population, KAM is reported to have two peaks: one at mid-stance and the other at the terminal stance phase [25,26]. A previous study of the relation of ankle DF and KAM investigated the association of ankle DF and KAM during the terminal stance; the findings of the present study confirmed the association between restricted ankle DF angle and the 1st KAM. An ankle DF angle reduction of $4.3^{\circ}\left(3.7^{\circ}\right.$ to $\left.-0.6^{\circ}\right)$ and $7.3^{\circ}\left(10.1^{\circ}\right.$ to $2.8^{\circ}$ ) during 1 st and 2 nd halves of the stance phase increased the KAM by $5 \%$ and $27 \%$, respectively. A previous report indicated that approximately $10^{\circ}$ of ankle DF is needed during terminal stance with the maximum ankle DF required through the gait cycle [27]. Therefore, the effect of reduced ankle DF on the KAM is thought to be larger during terminal stance (the $2^{\text {nd }}$ half of the stance phase).

In women, the increased KAM in the $2^{\text {nd }}$ half of the stance phase related not only to decreased ankle DF, but also to a decreased knee flexion angle (increased knee extension angle) (Table 2). Because we did not investigate how restricting ankle DF led to an increased KAM, we conducted a multiple regression analysis using the change in the KAM (dependent value) and the change in both ankle DF and the knee flexion angle (independent values) as additional factors. Together, the decreased ankle DF angle and decreased knee flexion angle (increased knee extension angle) explained $24 \%$ of the increased KAM in women. The mean knee flexion angle during the $2^{\text {nd }}$ half of the stance phase was $-2.0^{\circ} \pm 5.7$ $\circ$ (Table 1) indicating hyperextension of the knee. Joint laxity in women [20-22] which predisposes women to knee hyperextension, might be the influencing factor of the finding of the increased KAM. Additionally, hyperextension can lead to low proprioception of the knee joint [28], which is assumed to result in poor control of knee joint function and biomechanics.

From these findings, restricting the ankle DF angle in women could affect the knee joint angle, leading to a higher KAM compared with that in men. Previous studies reported that an increase in the KAM is related to progression of medial knee OA [7-9], and the prevalence rate of knee $\mathrm{OA}$ is higher in women than in men [1]. Women are particularly predisposed to age-related ankle DF restriction [18]. The present finding might support the use of range of motion exercises to increase ankle DF to reduce the KAM and prevent knee OA, especially in women.

The present study revealed a relationship between decreased ankle DF angle and knee hyperextension during both halves of the stance phase. The $4-5^{\circ}$ of restricted ankle DF in the present study led to a $4-5^{\circ}$ decrease in the knee flexion angle during the 1 st and 2nd stance phases in all participants. Several studies have reported the influence of decreased ankle DF angle on knee hyperextension in mid-stance during the 1 st half of the stance phase $[27,29,30]$ Perry
[27] described the compensation pattern induced by restricted ankle DF as flat foot with a posteriorly restrained tibia and poor rocker function during the $1^{\text {st }}$ half of the stance phase. This relation in the sagittal plane was observed in the $2^{\text {nd }}$ half of the stance phase in men, but the correlation was not significant in women. In women, angle restriction resulted in a knee flexion angle of $-2.0^{\circ}$ (i.e., $2.0^{\circ}$ of knee extension). We assume that the lack of a significant correlation was due to a ceiling effect for knee hyperextension.

Restricted ankle DF due to ankle and subtalar arthrodesis [31] and total ankle replacement [32] result in biomechanical changes to the gait, with the peak ankle DF angle during gait changing from $4.9^{\circ}$ and $7^{\circ}$, respectively, to $6.4^{\circ}$ and $6^{\circ}$ after the operations. The postoperative changes in the ankle DF angle were similar to restriction of the ankle DF angle in the present study. The total ankle replacement decreased the ankle pain, thereby improving walking speed and cadence [32]. The amount of ankle DF obtained for the terminal stance postoperatively was not adequate. The impact of the postoperative decrease in ankle DF and its influence on the knee joint, especially in women, should be considered. The studies did not evaluate other components of the knee joint biomechanics, such as KAM.

The present study has several limitations. The brace was one size and only fitted to the right ankle. The amount of reduction in the ankle DF angle could not be controlled for each subject. Therefore, we evaluated the correlation between a reduced ankle DF and other biomechanical values. We could not determine the amount of the decrease in the ankle DF angle that results in increased KAM for the $1^{\text {st }}$ and $2^{\text {nd }}$ halves of the stance phase. In addition, because the ankle DF restriction was immediate and forced, we could not assess the long-term effects of restricted ankle DF. Finally, a third limitation is that the subjects were all healthy and young, and the effects of restricted ankle DF should also be evaluated in middleaged subjects with a greater prevalence of knee OA.

\section{Conclusion}

Restricted ankle DF induced using a custom-made brace correlated with the increase in the KAM during the $1^{\text {st }}$ and $2^{\text {nd }}$ halves of the stance phase in women, but not in men. The increase in the $2^{\text {nd }} \mathrm{KAM}$ in women significantly correlated with a decrease in the ankle DF angle and an increase in the knee extension angle. Compared with men, women are more predisposed to an increased KAM due to decreased ankle DF.

\section{Acknowledgement}

The authors would like to thank Mr. Hirotaka Sato for assistance with the data collection and analysis. No funding was received for this study.

\section{Conflict of interest}

None of the authors declares any conflicts of interest in this study. 


\section{References}

1. Yoshimura N, Muraki S, Oka H, Mabuchi A, En Yo Y, et al. (2009) Prevalence of knee osteoarthritis, lumbar spondylosis, and osteoporosis in Japanese men and women: the research on osteoarthritis/osteoporosis against disability study. J Bone Miner Metab 27(5): 620-628.

2. Lawrence RC, Felson DT, Helmick CG, Arnold LM, Choi H, et al. (2008) Estimates of the prevalence of arthritis and other rheumatic conditions in the United States. Part II. Arthritis Rheum 58(1): 26-35.

3. Han KT, Wang PC (2018) Empirical examinations of effects of three-level green exercise on engagement with nature and physical activity. Int J Environ Res Public Health 15(2): 375.

4. Jackson BD, Wluka AE, Teichtahl AJ, Morris ME, Cicuttini FM (2004) Reviewing knee osteoarthritis--a biomechanical perspective. J Sci Med Sport 7(3): 347-357.

5. Zhao D, Banks SA, Mitchell KH, DLima DD, Colwell CW, et al. (2007) Correlation between the knee adduction torque and medial contact force for a variety of gait patterns. J Orthop Res 25(6): 789-797.

6. Andriacchi TP, Mundermann A, Smith RL, Alexander EJ, Dyrby CO, et al. (2004) A framework for the in vivo pathomechanics of osteoarthritis at the knee. Ann Biomed Eng 32(3): 447-457.

7. Miyazaki T, Wada M, Kawahara H, Sato M, Baba H, et al. (2002) Dynamic load at baseline can predict radiographic disease progression in medial compartment knee osteoarthritis. Ann Rheum Dis 61(7): 617-622.

8. Chehab EF, Favre J, Erhart Hledik JC, Andriacchi TP (2014) Baseline knee adduction and flexion moments during walking are both associated with 5 years cartilage changes in patients with medial knee osteoarthritis Osteoarthritis Cartilage 22(11): 1833-1839.

9. Chang AH, Moisio KC, Chmiel JS, Eckstein F, Guermazi A, et al. (2015) External knee adduction and flexion moments during gait and medial tibiofemoral disease progression in knee osteoarthritis. Osteoarthritis Cartilage 23(7): 1099-1106.

10. Jenkyn TR, Hunt MA, Jones IC, Giffin JR, Birmingham TB (2008) Toe-out gait in patients with knee osteoarthritis partially transforms external knee adduction moment into flexion moment during early stance phase of gait: a tri-planar kinetic mechanism. J Biomech 41(2): 276-283.

11. Shull PB, Silder A, Shultz R, Dragoo JL, Besier TF, et al. (2013) Six-week gait retraining program reduces knee adduction moment, reduces pain, and improves function for individuals with medial compartment knee osteoarthritis. J Orthop Res 31(7): 1020-1025.

12. Ota S, Ogawa Y, Ota H, Fujiwara T, Sugiyama T, et al. (2017) Beneficial effects of a gait used while wearing a kimono to decrease the knee adduction moment in healthy adults. PLoS One 12(6): e0179260.

13. Simic M, Hunt MA, Bennell KL, Hinman RS, Wrigley TV (2012) Trunk lean gait modification and knee joint load in people with medial knee osteoarthritis: the effect of varying trunk lean angles. Arthritis Care Res (Hoboken) 64(10): 1545-1553.

14. Ota S, Ueda M, Aimoto K, Suzuki Y, Sigward SM (2014) Acute influence of restricted ankle dorsiflexion angle on knee joint mechanics during gait. Knee 21(3): 669-675.

15. Youdas JW, McLean TJ, Krause DA, Hollman JH (2009) Changes in active ankle dorsiflexion range of motion after acute inversion ankle sprain. J Sport Rehabil 18(3): 358-374.
16. Lin CW, Moseley AM, Herbert RD, Refshauge KM (2009) Pain and dorsiflexion range of motion predict short- and medium-term activity limitation in people receiving physiotherapy intervention after ankle fracture: an observational study. Aust J Physiother 55(1): 31-37.

17. Donoghue OA, Harrison AJ, Coffey N, Hayes K (2008) Functional data analysis of running kinematics in chronic Achilles tendon injury. Med Sci Sports Exerc 40(7): 1323-1335.

18. Vandervoort AA, Chesworth BM, Cunningham DA, Paterson DH Rechnitzer PA, et al. (1992) Age and sex effects on mobility of the human ankle. J Gerontol 47(1): M17-M21.

19. McKay MJ, Baldwin JN, Ferreira P, Simic M, Vanicek N, et al. (2017) Normative reference values for strength and flexibility of 1,000 children and adults. Neurology 88(1): 36-43.

20. Larsson LG, Baum J, Mudholkar GS (1987) Hypermobility - features and differential incidence between the sexes. Arthritis Rheum 30(12): 14261430 .

21. Nguyen AD, Shultz SJ (2007) Sex differences in clinical measures of lower extremity alignment. J Orthop Sports Phys Ther 37(7): 389-398.

22. Scerpella TA, Stayer TJ, Makhuli BZ (2005) Ligamentous laxity and noncontact anterior cruciate ligament tears: a gender-based comparison. Orthopedics 28(7): 656-660.

23. Sekiya N, Nagasaki H, Ito H, Furuta T (1997) The invariant relationship between step length and step rate during free walking. J Hum Mov Stud 30: 241-257.

24. Davis III RB, Õunpuu S, Tyburski D, Gage JR (1991) A gait analysis data collection and reduction technique. Hum Movement Sci 10(2): 575-587.

25. Foroughi N, Smith R, Vanwanseele B (2009) The association of external knee adduction moment with biomechanical variables in osteoarthritis: a systematic review. Knee 16(5): 303-309.

26. Kadaba MP, Ramakrishnan HK, Wootten ME, Gainey J, Gorton G, et al. (1989) Repeatability of kinematic, kinetic, and electromyographic data in normal adult gait. J Orthop Res 7(6): 849-860.

27. Perry J (1992) Gait analysis: Normal and pathological function. Thoroface: Slack Incorporated.

28. Loudon JK (2000) Measurement of knee-joint-position sense in women with genu recurvatum. J Sport Rehabil 9(1): 15-25.

29. Klotz MCM, Wolf SI, Heitzmann D, Gantz S, Braatz F, et al. (2013) The Influence of Botulinum Toxin A Injections into the Calf Muscles on Genu Recurvatum in Children With Cerebral Palsy. Clin Orthop Relat Res 471(7): 2327-2332.

30. Svehlik M, Zwick EB, Steinwender G, Saraph V, Linhart WE. (2010) Genu recurvatum in cerebral palsy-part A: influence of dynamic and fixed equinus deformity on the timing of knee recurvatum in children with cerebral palsy. J Pediatr Orthop B 19(4): 366-372.

31. Tenenbaum S, Coleman SC, Brodsky JW (2014) Improvement in gait following combined ankle and subtalar arthrodesis. J Bone Joint Surg Am 96(22): 1863-1869.

32. Brodsky JW, Polo FE, Coleman SC, Bruck N (2011) Changes in gait following the Scandinavian Total Ankle Replacement. J Bone 93(20):1890-1896. 


\section{ISSN: 2574-1241}

DOI: 10.26717/BJSTR.2019.23.003932

Susumu Ota. Biomed J Sci \& Tech Res

(C) (P) This work is licensed under Creative Submission Link: https://biomedres.us/submit-manuscript.php

$\begin{array}{ll}\text { BIOMEDICAL } & \text { Assets of Publishing with us } \\ \text { RESEARCHES } & \text { - Global archiving of articles } \\ & \text { - Immediate, unrestricted online access } \\ & \text { - Rigorous Peer Review Process } \\ \end{array}$

